\title{
Sectorial ULCs as Measures of Competitiveness: An Analysis of Southern Euro Area Economies
}

\author{
Noel Rapa \\ Senior Research Economist, Research Office, Economics and Research Department, Central Bank of Malta \\ Email: rapan@centralbankmalta.org
}

\section{Doi:10.5901/mjss.2016.v7n6p17}

\section{Abstract}

This article analyses developments in the international cost competitiveness of six southern euro area economies using newly developed Effective Exchange Rate indices. It argues that traditional aggregate ULC-based indicators suffer from a number of limitations. In particular, they are affected by shifts towards more labour intensive industries and are also susceptible to global trends in the ULCS of particular sectors. In this light, this article computes sectorial ULC-deflated Effective Exchange Rate indices for a selection of southern euro area economies, which apart from providing more detail at a sectorial level, are more robust to structural changes. The newly developed indicators show a considerable degree of heterogeneity in the sectorial competitiveness developments of some economies. Moreover the newly developed overall economy sectorial ULC-deflated indices tend to diverge considerably from the traditional aggregate ULC-based indicators for small open economies that have been undergoing fast structural changes. In particular, the use of traditional ULC-based indicators tends to over-state the loss in competitiveness for economies that have either a fast-growing, or a larger than average services sector.

Keywords: Unit labour costs, competitiveness, structural changes, sectorial effective exchange rate indices.

\section{Introduction}

Both the global financial crisis of 2008 and more recently the sovereign debt crisis of 2012 have led to a renewed interest in the study of the determinants of international competitiveness. This issue is seen as even more crucial to economies in the euro area, which in the absence of independent exchange rate and monetary policies are forced to regain competitiveness through, most often painful, internal devaluation processes. For this reason, international institutions, most notably the European Commission and the ECB, have highlighted the need of structural reforms aimed at correcting the external imbalances of the Eurozone member countries which have been accumulating external deficits for a number of years. In this light, a correct measurement of international competitiveness is crucial to help policy makers in devising policies aimed at correcting the external imbalances of an economy.

Despite the complexity underlying the analysis of international competitiveness, most policymakers have relied on simple aggregate ULC-based measures to provide an indication of changes in the competitiveness position of economies. The importance of ULCs as indicators of competitiveness is confirmed by their inclusion in the MacroEconomic Imbalance Procedure of the European Union. Indeed, in an attempt to correct the external imbalances being accumulated by economies at the periphery of the Eurozone, most policymakers have advocated the need for a downward adjustment in the aggregate ULCs of these economies via a reduction in relative wages or an increase in productivity. However, the importance given to aggregate ULCs and aggregate ULC-based indicators as measures of international competitiveness might not be well deserved, especially when considering their well-known limitations. Indeed, developments in ULCs can be affected by shifts towards more labour intensive industries and are also susceptible to global trends in the ULCs of particular sectors.

Against this backdrop, this study attempts to shed some light on developments in the cost competitiveness of a selection of southern European economies, regarded to be part of the Eurozone periphery, namely Greece, Spain, France, Italy, Cyprus and Malta. The choice of these countries is motivated by the fact that these economies are relatively very open to international trade and have recently experienced sharp increases in their aggregate ULCs, at face value implying a deterioration of their competitiveness levels. Despite the limitations of this indicator, policy discussions at an international level have ensued in an attempt to lower the aggregate ULC indices of these economies, thus helping them regain their lost international competitiveness. In the light of the relevance of international competitiveness and considering the limitations of aggregate ULC-based indicators, this article aims to measure changes in the competitiveness of a number of southern euro area economies, through the use of sectorial ULC-based indicators designed to address the issues affecting other widely used indicators. 
The next section defines the concept of international competitiveness and describes a number of indicators traditionally used to measure changes in competitiveness. Section 3 provides a critique of aggregate ULC-based measures and puts forward their main shortcomings as indicators of international competitiveness. This section also proposes an alternative measure of cost competitiveness based on sectorial ULCs. Section 4 presents and analyses the main results. Finally, the last section draws some conclusions and policy recommendations.

\section{Defining and Measuring Competitiveness - A Literature Review}

While international competitiveness is consensually regarded as a key driver of sustainable economic growth, properly defining this concept has always proved to be a key analytical challenge. Broadly speaking, international competitiveness can be defined either from a long run or short run perspective (see Mann, 1999 and De Broeck, Guscina \& Mehrez, 2012). The former concept defines competitiveness in terms of the long term growth potential of an economy and is thus associated with the productivity of its factors of production. When analysed from this perspective, the determinants of competitiveness are often seen as qualitative in nature, and are therefore regarded as difficult to quantify. In this respect, the Global Competitiveness Report compiled by the World Economic Forum provides a comprehensive assessment of international competitiveness that includes a set of factors that affect the long term productivity of economies. Due to the difficulties usually encountered when measuring competitiveness from the long run perspective, most economists and policymakers choose to focus on the short run definition of competitiveness, namely that defined in terms of price and cost misalignments. Assuming that prices are defined as a mark-up over marginal costs, changes in the short run competitiveness of an economy can be driven either by changes in the costs incurred by firms, by changes in the market structure in which firms are operating (implying a change in the mark-up) or else, by a change in the exchange rate of an economy. This concept of competitiveness is often regarded as narrow and incomplete as it abstracts from other qualitative issues of competitiveness such as the quality of goods and services exported. However, recent literature $(E C B, 2012)$ suggests that the trade deficits experienced by southern European economies prior to the Eurozone crisis has been largely due to divergence in relative prices.

Apart from the conceptual ambiguity surrounding this concept, the study of international competitiveness has been affected by a number of difficulties that are usually encountered in measuring changes in the competitiveness of a nation. Despite the vast amount of literature that can be found on this topic, there is no clear consensus on how to best measure international cost or price competitiveness. The problems associated with measuring international cost or price competitiveness have been extensively explored by policy institutions such as central banks, the International Monetary Fund and the Bank of International Settlement. Seminal contributions in this respect include Hirsch and Higgins (1970) as well as Artus and Rhomberg (1976). More recently, studies by Turner and Van't dack (1993), Zanello and Desruelle (1997) as well as Cerra, Soikkeli and Saxena (2003) offer in depth reviews of the main issues surrounding the computation of international competitiveness measures. One such issue relates to the choice of either price or cost-based measures for measuring competitiveness. Zanello and Desruelle (1997) as well as Cerra, Soikkeli \& Saxena (2003) argue that in general, cost-based measures are deemed superior to price-based measures as they analyse a larger component of the costs of tradable goods and services. In view of data availability challenges concerning the productivity and costs of capital, often only the costs related to one factor of production, labour, are usually considered in the analysis. Moreover, since capital goods are traded internationally, returns to capital are more easily subject to the law of one price (Cerra, Soikkeli \& Saxena, 2003). In this light, the focus on labour costs for the purposes of competitiveness analysis seems well justified.

A very popular indicator in this respect is aggregate ULC, defined as the ratio of a workers' compensation per employee to labour productivity. Apart from being convenient from a statistical view point, this index describes the developments of the largest component of non-traded costs and of value added, thus serving as a good proxy for the evolutions in total costs. However, ULCs are unit less measures that need to be compared to a meaningful base. For this reason, policymakers usually compare ULCs of a specific country with that of a benchmark economy. In case of euro area economies, most analysis of peripheral economies is done in comparison to Germany or the euro area average. In this respect, chart 1 leads to the conclusion that the euro area periphery has lost competitiveness both vis-à-vis Germany and the euro area. Such a comparison, however, is somewhat simplistic and potentially misleading as it neglects differences in the export baskets of the economies under consideration as well as changes in the bilateral exchange rates.

In view of these deficiencies, policymakers and researchers often use ULC deflated Effective Exchange Rate (EER) indices which are a weighted average of bilateral exchange rate indices deflated by relative ULCs, with weights reflecting the relative importance of each economy with respect to the home country. Chart 2 shows the evolution of the ULC-deflated EER of the countries under consideration between 1996 and 2015. This analysis shows that all economies under consideration have lost competitiveness to the run-up of the financial crisis of 2009 , mainly due to stagnant 
productivity growth. Between 2012 and 2015, all economies, with the exception of Malta and Italy, have experienced improvements in their real EERs, potentially driven by austerity measures that have helped to reduce the wage growth of the economies that were most severely hit by the Eurozone crises. On the other hand Italian real EERs have remained quite constant during this period. Moreover, driven by a marked slowdown in productivity growth, Maltese real EERs have continued on their upward trend, potentially implying a worsening in competitiveness.

Chart 1: ULC index $(2000=100)$

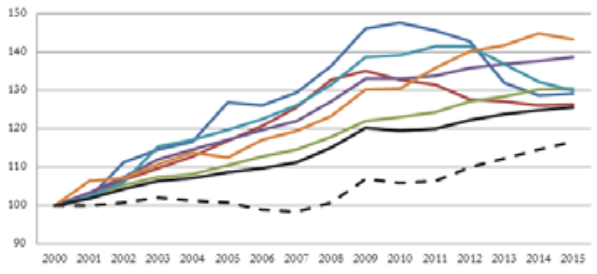

Source: Eurostat
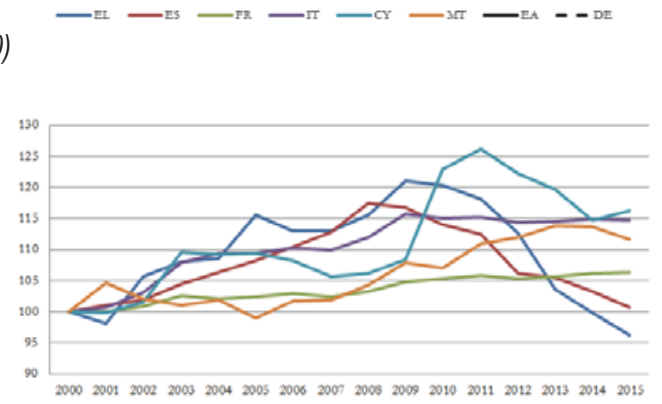

Chart 2: ULC-deflated EER index $(2000=100)$

Source: DGECFIN

\section{Methodology}

The policymakers' focus on the use of aggregate ULC based indicators for the analysis of competitiveness is perhaps not well-deserved, especially when considering the limitations of such measures. Historically, there has always been an ambiguous empirical relation between ULC growth and the external trade developments of economies; a result often referred to as Kaldor's paradox (Kaldor, 1970). Moreover, while the use of ULCs is perfectly reasonable at the firm level, the interpretation of this indicator at an aggregate or macro level is less clear (Felipe and Kumar, 2011). This is mainly due to two issues. First, movements in aggregate ULCs might be due to changes in the sectorial composition of the economy (Honohan and Walsh, 2002). To see this more clearly, it is convenient to decompose aggregate ULCs as follows:

$$
U L C_{t}=\frac{C P E_{t}}{P R O D_{t}}=\frac{C O M P_{t}}{L_{t}} * \frac{L_{t}}{R G D P_{t}}=S_{t}^{L} * P_{t}
$$

Where $C P E_{t}$ is compensation per employee, $P R O D_{t}$ is real productivity, $C O M P_{t}$ is compensation of employees, $L_{t}$ is employment, $R G D P_{t}$ is real GDP, $S_{t}^{L}$ is the share of labour in overall nominal GDP and $P_{t}$ is the overall GDP deflator. This decomposition shows that a move towards more labour intensive sectors implies an increase in aggregate ULCs, even if there is no change in each sector's competitiveness. The second issue of aggregate ULCs is that such indicators are affected by different global developments of ULCs across sectors (De Broeck, Guscina and Mehrez, 2012). For instance if the country under analysis specialises in a sector in which global ULCs are increasing, aggregate relative ULCs of the home country would experience an automatic increase, even if no changes occur in relative ULCs at a sector level.

In the light of these weaknesses, this study follows the approaches of the European Commission (2014) and Cerra, Soikkeli \& Saxena (2003) and computes sector based ULC indices for the Eurozone peripheral economies. These indices are then used to deflate nominal sectorial EERs which are in turn computed as the geometric mean of nominal bilateral exchange rates. More specifically:

$$
R E E R_{j}^{i}=\prod_{k}\left(\frac{u l c_{j}^{i}}{u l c_{j}^{k}} e^{i, k}\right)^{\psi_{j}^{i, k}}
$$


Where $R E E R_{j}^{i}$ is the ULC-deflated real EER of country $i$ in sector $j, u l c_{j}^{k}$ is the unit labour cost in sector $j$ in country $k$, and $e^{i, k}$ is the bilateral exchange rate. $\psi_{j}^{i, k}$ is the weight given to country $k$ in the computation of the real EER of country $i^{1}$. Despite its apparent superiority, a double-weighting scheme could not be used due to the lack of data on bilateral service trade flows. In this light, the weights used in this exercise are computed using a simple weighting scheme given by:

$$
\psi_{j}^{i, k}=\frac{G V A_{j}^{k}}{\left(\sum_{k} G V A_{j}^{k}\right)-G V A_{j}^{i}}
$$

Where $G V A_{j}^{k}$ is the gross value added of sector $j$ in economy $k$. Given that the denominator excludes sector $j$ gross value added of the home economy, the weights computed though this method will be both sector and country dependent. The final step involved in computing a sector based real EER is to aggregate the sectorial real EERs using the relative size of each sector in the home country:

$$
R E E R^{i}=\sum_{j}\left(w_{j}^{i} * R E E R_{j}^{i}\right)
$$

Where $R E E R^{i}$ is the overall sectorial real EER of country $i$, and $w_{j}^{i}$ is the relative share of sector $j$ in country $i$, and is calculated as:

$$
w_{j}^{i}=\frac{G V A_{j}^{i}}{\sum_{j} G V A_{j}^{i}}
$$

With regards to the number of sectors taken under consideration, there is a trade-off between the level of disaggregation and the availability and quality of the underlying data. The higher the level of disaggregation chosen, the less will the resulting real EERs be affected by the aggregation issues mentioned above. On the other hand, moving towards higher levels of disaggregation makes analysis of results harder especially due to the unavailability of data for GVA deflators at a sectorial level for Malta as well as due to the quality of employment and GVA data at such high levels of disaggregation. For this reason I choose to keep disaggregation at a minimum and compute sector dependent ULCs and real EERs for the services and industry sectors².

Moreover, due to data availability issues, the number of countries included in the sample of trading partners was limited to the EU 28 group of economies. Despite including only EU economies, the dataset used in this study covers a significant part of each country's exports. Nevertheless, the omission of non-EU trading partners, such as the United States, Japan and China could be affecting results, especially for economies such as Malta, which are relatively more open to extra-EU trade. The sample period considered in this study was also limited by the availability of comparable data and spans the period between 2000 and 2015.

\section{Results and Discussion}

\subsection{Sectorial ULCS}

Chart 3 plots the ULC indices of both industry and services sectors for the countries considered in this study. It is immediately noticeable that all ULC indices (with the exception of the industry ULC for Malta) have been on an upward trend for most of the period under consideration. Moreover, one can note that the growth in services sector ULCs has outstripped that registered in its industry counterpart in five out of the six countries under consideration. Indeed, average annual growth in services ULCs across the countries under consideration stood at $1.8 \%$, higher than the 1.3\% average growth registered in the industry sector. Looking at the underlying developments of compensation per employee and productivity, one can note that lacklustre growth in the latter has been the main driver of these results. On average compensation per employee growth in the services sector has been relatively subdued when compared to that registered in the industry sector. However, these developments have been relatively outweighed by even slower productivity growth in the services sector, causing services ULC growth to exceed that registered in the industry sector. Considering the nature of the services and industry sectors, these developments are not surprising. The services sector is generally

\footnotetext{
${ }^{1}$ Note that these calculations are repeated across time. However, the time subscript is eliminated for simplicity.

2 The services sector is defined as all services sectors excluding public while the industry sector includes industrial production excluding construction. For the purpose of this exercise, both construction and public administration were excluded from the computation of the sectorial ULCs. Note however that the results presented in this study are robust to the inclusion of these sub-sectors in the analysis. Also, since no data on sector GVA deflators are available for Malta, the industrial Purchase Price Index (PPI) and the overall GDP deflator were used to deflate, industrial production and services for all countries considered in this exercise. Results are also robust to the use of the goods exports deflator and the overall GDP deflator as proxies for the industry GVA deflator.
} 
regarded to experience slower productivity growth when compared to the industry sector. Indeed, the latter tends to benefit from technological improvements that lead to increased automation thereby boosting productivity and limiting ULC growth in this sector. This result suggests that the services sector is likely to possess an excessive trend at a global level. This, together with the limitations of traditional aggregate indicators explored above, suggests aggregate ULC-based indicators could be potentially overestimating losses in competitiveness in more service oriented economies.

One can note that throughout the period under consideration, Greece and Cyprus have registered the highest increases in their ULCs prior to the Eurozone recession of 2012. Driven by stagnant productivity, both Greek sectors have experienced a significant increase in their respective ULCs of around $50 \%$ to $60 \%$ between 2000 and 2010. On the other hand, Cyprus has experienced diverging trends in the performance of its sectors. The Cypriot services industry has registered increases in its ULC index which were in line with those of the other countries included in this study. On the other hand, lacklustre productivity growth coupled with a sudden increase in the industry sector compensation per employee, have driven this sector's ULCs up by almost $80 \%$ between 2000 and 2012 . Although to a lesser extent, the Italian economy has also experienced significant increases in its sectorial ULCs. In the case of the industrial sector, the main driver behind these increases has been average compensation per employee, which has grown by around $40 \%$ in the period under consideration. On the other hand, falls in the productivity of the services sector have been the main driver behind this sector's ULC increases, as compensation per employee growth remained relatively subdued. During the same period the ULC indices of France and Malta have experienced less pronounced increases, with the Maltese industry ULCs even falling, driven by positive developments in productivity. The fall in the Maltese industry ULCs coincide with Malta's accession to the European Union, which was accompanied by a series of structural reforms aimed at shifting the economy from traditional to higher value-added sectors (Grech, 2015a).
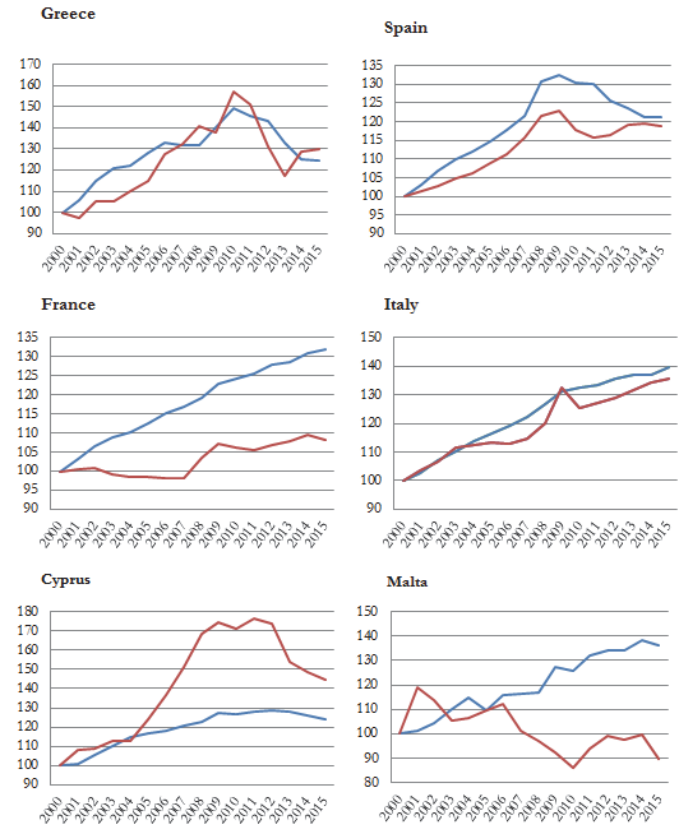

Chart 3: Sectorial ULCs $(2000=100)$

Source: Author's calculations

Between 2012 and 2015, almost all Mediterranean economies hit by the Eurozone crisis (with the exception of Italy) have registered falls in their sectorial ULCs, potentially driven by the austerity measures implemented across the euro area ${ }^{3}$.

\footnotetext{
${ }^{3}$ Apart from Italy, even Malta's ULCs have failed to show improvements after the Eurozone crisis. However, the Maltese economy was largely unaffected by the debt crisis of 2012. As a result, during this period Malta has not carried out any austerity measures aimed at reducing its labour costs relative to productivity.
} 
These reductions in sectorial ULCs have been mostly driven by a slow-down in compensation per employee growth, indicating that the structural reforms implemented in program countries are still not helping to boost labour productivity (see for instance Cyprus and Greece). It is also interesting to note, that despite the implementation of austerity measures, the sectorial ULCs for Italy have continued increasing at their pre-crisis trends, indicating an inability to effectively correct its compensation per employee growth to match more closely developments in productivity.

\subsection{Sectorial ULC-deflated EERs}

Chart 4 shows the result of sectorial ULC-deflated EERs for the economies under consideration between 2000 and 2015. These results show that after correcting for both bilateral exchange rate changes as well as for movements in the ULCS of their respective competitors, most of the countries under consideration have lost competitiveness in both sectors throughout the period under consideration. Moreover, results show that there has been a considerable degree of heterogeneity in the developments of real EERs across both sectors and economies. Greece and Cyprus are the two nations that have experienced the highest deteriorations in their cost competitiveness at least in the first part of the sample under consideration. In the Greek case, both sectors have experienced a substantial worsening in their cost competitiveness, with peak appreciations of around $43 \%$ and $27 \%$ being registered in the services and industry sectors by 2010. The Cypriot economy has experienced diverging developments in its sectorial cost competitiveness. Driven entirely by developments in its relative ULCs, the cost competitiveness of the Cypriot industry sector has worsened substantially, registering an appreciation in excess of $70 \%$ by 2010. On the other hand, the appreciation of the Cypriot services sector EER has been relatively more contained, reaching a peak of less than $20 \%$. The appreciation registered in the sectorial EERs of the rest of the economies under consideration is more contained (perhaps with the exception of Italy which has experienced an appreciation of around 15\% in both sectors). Furthermore, Malta is the only nation that has experienced gains in its sectorial cost competitiveness, registering significant gains in the competitiveness of its industrial sector. Indeed, helped by a number of structural reforms and the switch to higher value added manufacturing, Malta's industrial competitiveness improved considerably immediately after its accession to the European Union. Finally, results also show that with the exception of the developments recorded in Cyprus and France, the services sector of all economies considered in this sample have registered real EER appreciations that exceed those registered in the industry sector.
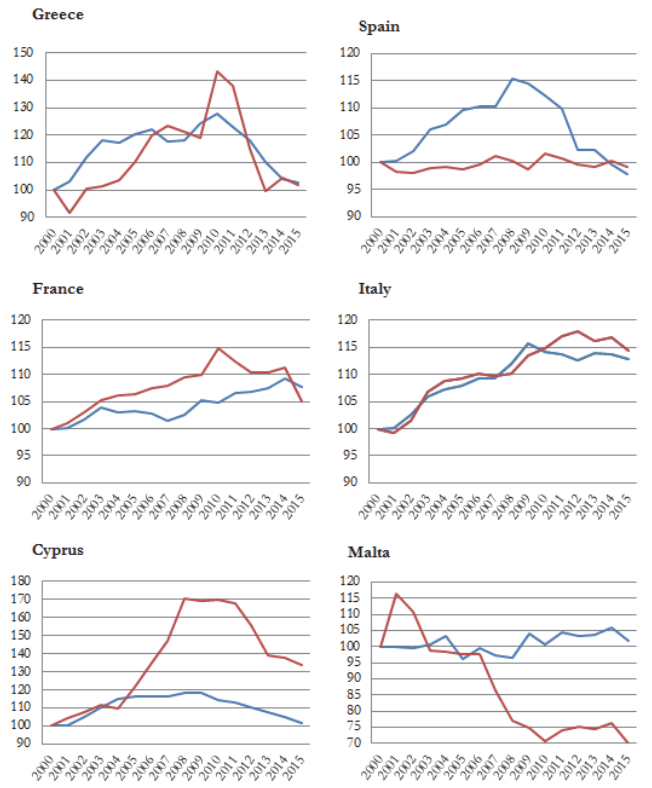

Chart 4: Sectorial EERs $(2000=100)$

Source: Author's calculations

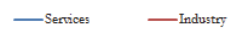




\subsection{Overall sector based EERs}

Chart 5 plots each nation's overall real EER based on sectorial ULCs and compares them with the publicly available aggregate ULC-based EERs ${ }^{4}$. To aid in the interpretation of results, the graphs also plot the share of services in overall GVA. It is important to note that the computation of the overall EER, does not require the computation of an overall ULC index, but instead relies on the aggregation of two sectorial EER indices. As already noted, the services sector ULCs tend to increase at greater rates when compared to their industry counterparts, implying that service oriented economies would possess aggregate ULCs that are bound to grow at faster rates when compared to more industry oriented economies. By computing an overall EER index by aggregating sectorial EERs, the method proposed in this study is able to correct for any excessive trends that can be found in the services sector.

Results show that in the run up to the financial crisis of 2008, almost all economies considered in this study (with the exception of Malta) have lost some of their cost competitiveness. In line with their sectorial results, Greece and Cyprus have been the worst performers across the sample under consideration, followed by Italy, Spain, and France. During this period, these economies have seen their trade balances degrading rapidly, reaching a peak deficit position by 2009. The accumulation of unsustainable trade deficits has forced these economies to undergo internal devaluations in the form of structural reforms, aimed at boosting the productivity of their factors of production relative to their costs. The austerity measures undertaken after the global crisis and during the Eurozone debt crisis have helped almost all of these deficit countries (with the exception of France, and to a lesser extent Italy) to improve their international cost competiveness. Indeed, by 2015, Greece, Spain and Cyprus had already recouped most of the competiveness lost in the previous decade.

Contrary to the other economies under consideration, Malta's performance between 2000 and 2009 has been on the whole positive. The newly developed indicator shows that between 2000 and 2009, the Maltese economy has gained in its cost competitiveness position vis-à-vis its main trading partners. These results are consistent with Malta's external performance during this period. Traditionally, Malta's external position has ended in deficits close to $15 \%$ since the early 1990s. However, from 2000 onwards, Malta registered notable improvements in its trade balance, also succeeding in becoming a net exporter by 2011 (Grech, 2015b). Indeed a strong international trade performance has helped the Maltese economy weather the international financial crisis relatively well. After a brief recession in 2009, real GDP in Malta had surpassed its pre-crisis level by 2010 , with net exports featuring as the main contributor behind the rise in economic activity.

\subsection{Comparing overall sector based EERs with traditional ones - a discussion}

The latter results are at odds with those reported by traditional EER indicators. One can note that the traditional and the sectorial ULC-based indicators for Malta have diverged considerably across the sample period, with the former index indicating a loss in Maltese cost competitiveness. While the sectorial ULC-based EER shows a slight improvement in Maltese cost competitiveness between 2000 and 2015, the publicly available aggregate ULC-deflated EER shows a 12\% deterioration in Malta's cost competitiveness in the same period; developments that contrast sharply with the international performance of the Maltese economy (Micallef, 2015 and Rapa, 2016). The difficulty in reconciling the unfavourable developments in aggregate ULC-deflated EERs and the concurrent strengthening of Malta's external position can be explained by considering the limitations of this aggregate based indicator: mainly those related to its sensitivity to the level of as well as to change in the share of services in the overall economic activity of an economy.

\footnotetext{
${ }^{4}$ The aggregate ULC-deflated EERs are computed by the European Commission (DGECFIN) and have the same country coverage as the sectorial ULC-based EERs computed in the study.
} 

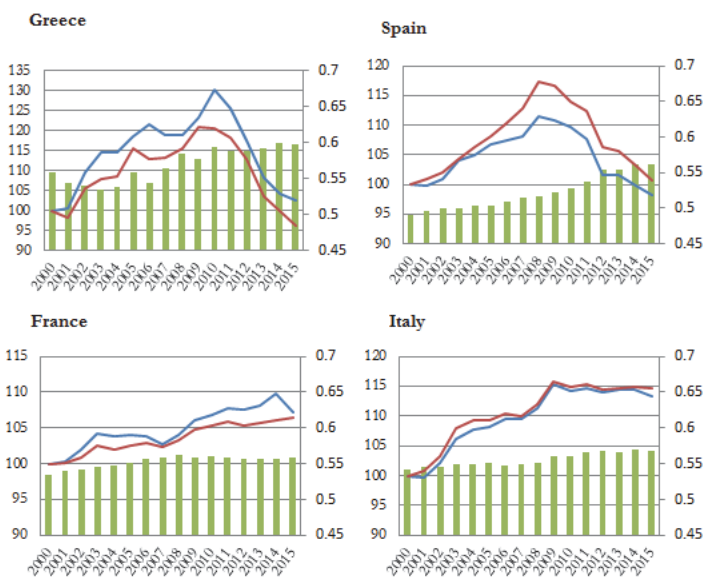

Italy
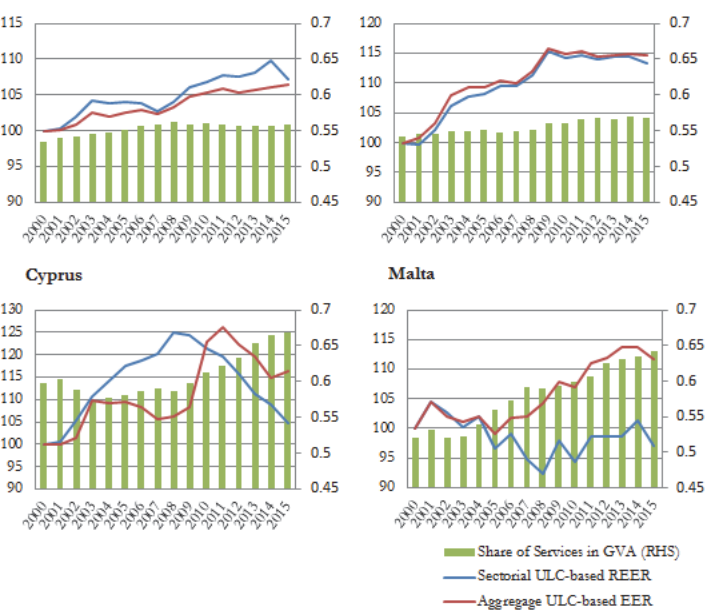

Chart 5: Sectorial ULCS $(2000=100)$

Source: Author's calculations, DGECFIN

Between 2000 and 2015, the Maltese economy has gone through a number of structural changes that have led to a diversification of its economic base. As shown by chart 5, during this period, Malta has seen an increase of 12pp in its share of services in overall GVA, the third highest increase in the European Union. By 2015, Maltese services GVA as percent of overall GVA stood at $64 \%$, the second highest amongst European Union economies. The move towards more labour intensive sectors as well as a higher reliance on sectors in which ULCs grow at faster rates, are likely to cause an upward bias in the aggregate ULC-based EER which is however attenuated by the methods proposed in this study.

As shown by the results of chart 5 , the divergences between aggregate and sectorial ULC-deflated EERs vary considerably across economies. Generally, these divergences tend to be more pronounced for small open economies that have been undergoing fast structural changes, such as Cyprus and Malta. Traditional aggregate ULC-based measures tend to over-estimate the loss of competitiveness of economies that have either a fast growing, or a larger than average service sector. In Cyprus' case for instance, one can note that the traditional EER underestimates Cyprus' loss of competitiveness prior to the crisis, and is thus unable to explain the imbalances accumulated by Cyprus in the run up to the financial crisis. This underestimation can be explained by the falling share of services in overall output that occurred during this period. As the services sector started growing again after 2009, the aggregate ULC based EER started to overstate losses in competitiveness, failing to capture improvements in the cost competitiveness of Cyprus. A similar case holds for the Spanish economy. On the other hand the two measures do not tend to diverge for economies, such as Italy and to a lesser extent France, whose shares of services have remained relatively stable over time and where the output mix between services and industry is close to that of their competitors. The only exception to these arguments seems to be Greece. Despite its gradual move towards a more service oriented economy, the sectorial ULCbased EER shows an underestimation of Greece's loss in competitiveness that has characterised its economy in the last 15 years. In fact, the new competitiveness indicator suggests that the notwithstanding the measures undertaken in an effort to boost its competitiveness levels, the Greek economy is still relatively less competitive when compared to the start of the sample period under consideration. 


\section{Conclusion}

Assessing international competitiveness is a key analytical and policy challenge, especially for economies within the euro area, which in the lack of independent monetary and exchange rate policies, must rely on internal devaluations to correct for unsustainable trade deficits. Despite their popularity within both academic and policy circles, the use of aggregate ULC based indicators is flawed by the inherent limitations of aggregate ULC indices. Indeed, aggregate ULC measures are very sensitive to changes in the sectorial composition of output and might by driven by changes in the economy's structure as well as by differences in the economies' sectorial composition.

Given these limitations as well as the lack of reported empirical evidence linking developments in aggregate ULCs and international trade, this study computes sector specific real EERs. When compared to their aggregate counterparts, these indices are less prone to changes in the economic structure of nations and are also able to correct for any excessive trends that some sectors might possess. For relatively small open economies characterised by a high share of services in overall GVA, such as those of Malta and Cyprus, the two measures tend to diverge considerably, especially during periods of economic restructuring which drive changes in the share of labour intensive sectors in overall economic activity. In Malta's case, the sectorial ULC-based indicator is consistent with the improvements in the trade balance experienced by the Maltese economy during the period under consideration. Similarly for Cyprus, the inability of traditional aggregate ULC-deflated EERs to explain the imbalances accumulated by the Cypriot economy prior to the financial crisis of 2008, highlights the validity of the new indicators proposed in this study. On the other hand, economies characterised by a share of services which is closer to that of their competitors and which have not experienced significant moves in their sectorial composition, (such as France and Italy) the two measures tend to be very close to each other.

The new indicators constructed in this study provide new interesting insights into international cost competitiveness and help to attenuate the limitations of traditional aggregate ULC-based indicators. Still, the methods proposed above suffer from a number of limitations that warrant further research into the area. Firstly, the sample of trading partners included in the computation of these indicators was limited to the EU-28 group of countries. Thus the results discussed above could potentially be affected by the exclusion of important trading partners such as the United States, Japan and China. Secondly, data availability and quality issues for the smaller economies under consideration have limited the degree of disaggregation that could be achieved. Thus, these results could still be to some extent affected by compositional effects that happen within the industry and services sectors. Moreover, as stressed earlier on in this study, the concept of cost competitiveness is rather limited as it excludes qualitative aspects of competitiveness that are especially valid in the long run. Against this backdrop, a comprehensive study of an economy's competiveness should also include an analysis of the productivity of a nation's factors of production. In this respect, a holistic analysis of an economy's level of competiveness should encompass indicators measuring the nation's level of education attainment, degree of market flexibility, technology uptake speed as well as the quality of its political and policymaking processes.

\section{References}

Artus, J.R., \& Rhomberg, R.R. (1973). A multilateral exchange rate model. International Monetary Fund Staff Papers, Vol. 20, No. 2, pp. 591-611.

Cerra, V., Soikkeli, V.J., \& Saxena, S.C. (2003). How competitive is Irish manufacturing? The Economic and Social Review, Vol 34, No. 2 Summer/Autumn, pp.173-193.

De Broeck, M., Guscina, A., \& Mehrez, G. (2012). Assessing competitiveness using industry Unit Labor Costs: an application to Slovakia. International Monetary Fund Working Paper No. 12/107.

European Central Bank. (2012). Competitiveness and external imbalances within the EA. Occasional Paper Series, No 139.

European Commission, (2014). A competitiveness measure based on sector unit labour costs. Quarterly Report on the Euro Area, Vol. 13, No. 2.

Felipe, J., \& Kumar, U. (2011). Unit labour costs in the Eurozone: the competitiveness debate again. Levy Economics Institute of Bard College Working Paper, No. 651.

Grech, A.G. (2015a). The diversification of the Maltese Economy. Central Bank of Malta Policy Note, September 2015.

Grech, A.G. (2015b). The evolution of the Maltese economy since Independence. Central Bank of Malta Working Paper, WP/05/2015.

Hirsch, F., \& Higgins, I. (1970). An indicator of effective exchange rates. International Monetary Fund Staff Papers, Vol. 17, No. 1, pp. 453-87.

Honohan, P., \& Walsh, B. (2002). Catching up with the leaders: The Irish hare. Brookings Papers on Economic Activity, No.1, pp. 1-77.

Kaldor, N. (1970). The Case for Regional Policies. Scottish Journal of Political Economy, Vol. 18 pp. 337-348. Reprinted in Scottish Journal of Political Economy

Mann, C.L. (1999). Is the U.S. trade deficit sustainable? Peterson Institute for International Economics. 
Micallef, B. (2015). Unit labour costs, wages and productivity in Malta: A sectorial and cross-country analysis. Central Bank of Malta Policy Note, August 2015.

Rapa, N. (2016). Measuring international competitiveness. In Grech, A.G. (Ed.), Understanding the Maltese Economy (pp. 25-33). Central Bank of Malta.

Turner, P. \& Van't dack, J. (1993). Measuring international price and cost competitiveness. BIS Economic Papers No. 39.

Zanello, A., \& Desruelle, D. (1997). A primer on the IMF's Information Notice System. International Monetary Fund Working Paper, WP/97/71. 